\title{
HALOE ANTARCTIC OBSERVATIONS IN THE SPRING OF 1991
}

\author{
James M. Russell III ${ }^{1}$, Adrian F. Tuck ${ }^{2}$, Larry L. Gordley ${ }^{3}$, Jae H. Park ${ }^{1}$, \\ S. Roland Drayson ${ }^{4}$, John E. Harries ${ }^{5}$, Ralph J. Cicerone ${ }^{6}$, and Paul J. Crutzen 7
}

\begin{abstract}
HALOE observations of $\mathrm{O}_{3}, \mathrm{CH}_{4}, \mathrm{HF}, \mathrm{H}_{2} \mathrm{O}, \mathrm{NO}$, $\mathrm{NO}_{2}$, and $\mathrm{HC} \ell$ collected during the October 1991 Antarctic spring period are reported. The data show a constant $\mathrm{CH}_{4}$ mixing ratio of about $0.25 \mathrm{ppmv}$ for the altitude range from $65 \mathrm{~km}$ down to about $25 \mathrm{~km}$ at the position of minimum wind speed in the vortex: i.e., the vortex center, and depressions in pressure versus longitude contours of $\mathrm{NO}, \mathrm{NO} 2, \mathrm{HF}$, and $\mathrm{HC} \ell$ in this same region. Water vapor, $\mathrm{HF}$, and $\mathrm{HC} \ell$ enhancement are also observed in the vortex center region above $\sim 25 \mathrm{~km}$. Between 10 and $20 \mathrm{~km}$, the expected mixing ratio signatures exist within the vortex, i.e., low ozone and dehydration. The water vapor increased by $50 \%$, and the ozone level doubled inside the vortex between October 11 and 24 in the 15 to $20 \mathrm{~km}$ layer. These changes imply a time constant for recovery from ozone hole conditions of 19 and 30 days for $\mathrm{O}_{3}$ and $\mathrm{H}_{2} \mathrm{O}$, respectively. The data further show the presence of air inside the vortex between 3 and $30 \mathrm{mb}$ which has mixing ratios characteristic of mid latitudes.
\end{abstract}

\section{Introduction}

The Halogen Occultation Experiment (HALOE) was launched September 12, 1991, by the Space Shuttle Discovery onboard the Upper Atmosphere Research Satellite (UARS) into a $57^{\circ}$ inclination, $585 \mathrm{~km}$, near-circular orbit. After allowing for a period of outgassing, the experiment started routine science observations on October 11,1991. HALOE uses the experiment principle of satellite solar occultation and the instrument techniques of gas filter and broadband radiometry to sound the middle atmosphere temperature versus pressure, $\mathrm{O}_{3}, \mathrm{HC} \ell, \mathrm{HF}$, $\mathrm{CH}_{4}, \mathrm{NO}, \mathrm{NO}_{2}$, and $\mathrm{H}_{2} \mathrm{O}$ vertical profiles [see Russell et al., 1993]. The solar occultation experiment coverage in the UARS orbit extends from $\sim 80^{\circ} \mathrm{S}$ to $80^{\circ} \mathrm{N}$ over the course of a year. From October 11 through November 1, 1991, HALOE observed over the range from about $50^{\circ} \mathrm{N}$ to $80^{\circ} \mathrm{S}$, providing a large number of profiles of the parameters measured. These data were collected in the early-to-middle stage of the Antarctic ozone hole recovery phase. Since the UARS spacecraft conducts a yaw maneuver about every 32 days, other UARS experiments (i.e., the limb emission sounders which view perpendicular to the velocity vector on the dark side of the spacecraft) were not observing the Antarctic region during this time. Because of the uniqueness of the HALOE observations and their implications for revealing processes operating during the ozone hole recovery period, we are providing this early report on our findings. The data shown and discussed later have not undergone the intensive scrutiny of a complete validation process, but the state of validation and internal data consistency are sufficient to establish the correctness of features which are highlighted.

HALOE measures long-lived tracers and reservoir species (i.e., $\mathrm{CH}_{4}, \mathrm{HF}, \mathrm{H}_{2} \mathrm{O}$, and $\mathrm{HC} \ell$ ), as well as photochemically active molecules (NO, $\mathrm{NO}_{2}$, and $\mathrm{O}_{3}$ ), all of which are important

\footnotetext{
1NASA Langley Research Center

2NOAA Aeronomy Laboratory

${ }^{3}$ G\&A Technical Software

${ }^{4}$ University of Michigan

5Rutherford Appleton Laboratory

6University of California/Irvine

${ }^{7}$ Max-Planck-Institute for Chemistry
}

Copyright 1993 by the American Geophysical Union.

Paper number 93GL00497

0094-8534/93/93GL-00497\$03.00 in understanding photochemical and dynamical processes which are occurring. A concise and thorough review of theories explaining the ozone hole phenomena has been presented by Solomon [1990]. In addition, a wealth of data and a collection of recent theories on polar phenomena are contained in three $J G R$ Special Issues on Polar Ozone and the Airborne Antarctic Ozone Experiment [Volume 97, D8, and Volume 94, D9 and D14, respectively]. It is now clear that for Antarctic ozone destruction to occur at the observed rate $(\sim 1$ to $2 \%$ per day) in late September and early October, there must be low temperatures (needed to cause polar stratospheric cloud formation), aerosols or polar stratospheric clouds (required as reaction surfaces to trigger chemical reactions that do not occur in the gas phase), enhanced chlorine to cause catalytic ozone destruction, and a stable vortex to form a kind of reaction or containment vessel. The extent to which the vortex is better viewed as a containment vessel [Juckes and McIntyre, 1987; Schoeberl et al., 1992] or as a flow reactor exporting ozone loss to mid-latitudes [Danielsen and Houben, 1988; Tuck, 1989; Proffitt et al., 1989a, b; Tuck et al., 1992] is currently controversial. The processes which occur in the ozone recovery period are less clear, mainly because of a lack of sufficient data. The purpose of this paper is to summarize HALOE observations in the late Antarctic spring of 1991 and to discuss their implications.

\section{Observations}

Figure 1 shows four ozone vertical profiles at $77^{\circ} \mathrm{S}$ on October 22, 1991. Note that the profiles vary longitudinally in an orderly way with the solid curve observed at $248^{\circ} \mathrm{E}$ giving the lowest mixing ratio. The total column ozone above $100 \mathrm{mb}$ is 138 D.U. for this profile and 258 D.U. for the profile which occurs at $175^{\circ} \mathrm{E}$. The $30 \mathrm{mb}$ analyzed wind field and $\theta=700 \mathrm{~K}$ potential vorticity (PV) map on this day provided by the European Centre for Medium-range Weather Forecasts (ECMWF) are shown in Figures $2 a$ and $b$, respectively. Note that all HALOE measurements are made well inside the vortex (as defined by the maximum winds or as judged by quasihorizontal (isentropic) PV gradients). The smallest column ozone occurs at the center of the vortex (set 7), while the largest value occurs nearer the vortex edge (set 13). Vertical profiles of $\mathrm{CH}_{4}$ and HF on this day are shown in Figures 3 and 4. There is a longitudinal ordering of the profiles as it is for ozone. We will expand here on the definition of "vortex center." Note that the geographical position of minimum wind velocity (Figure $2 a$ ) located around $(76 \mathrm{~S}, 300 \mathrm{E})$, is coincident with the methane profile, having a constant mixing ratio from $\sim 65 \mathrm{~km}(0.1 \mathrm{mb})$ to $\sim 25 \mathrm{~km}(25 \mathrm{mb}$ ) (solid curve in Figure 3 ). The point of zero

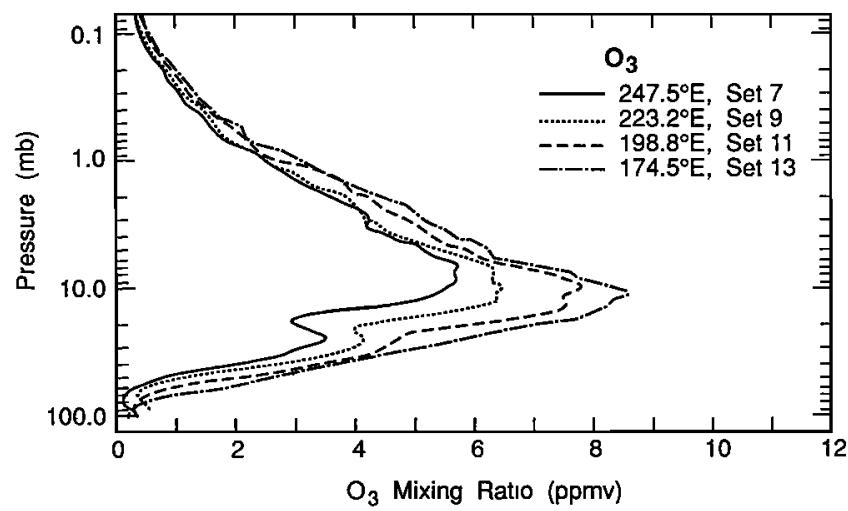

Fig. 1. HALOE pressure versus $\mathrm{O}_{3}$ mixing ratio, sunset on October 22, 1991, at $77^{\circ} \mathrm{S}$. 


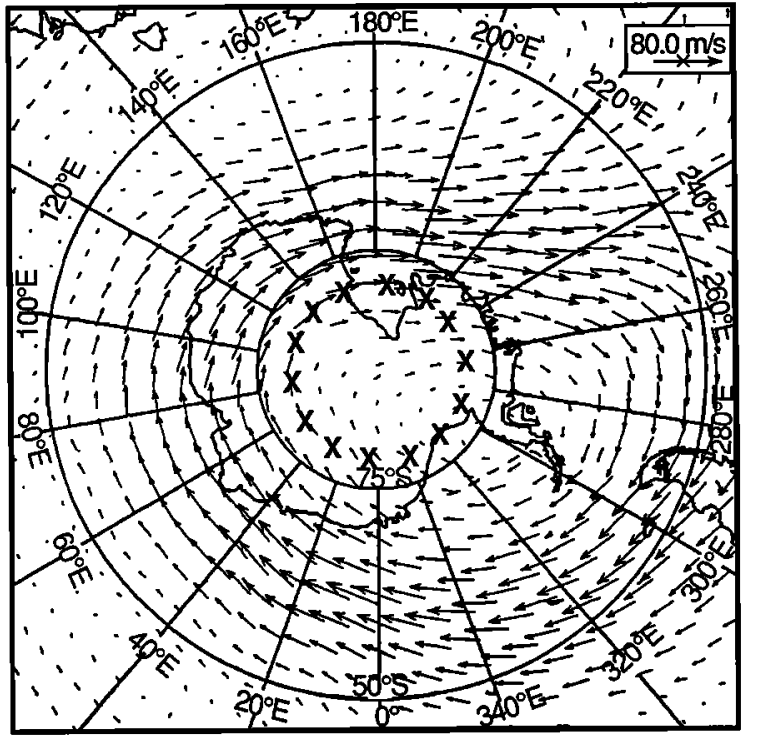

(a)

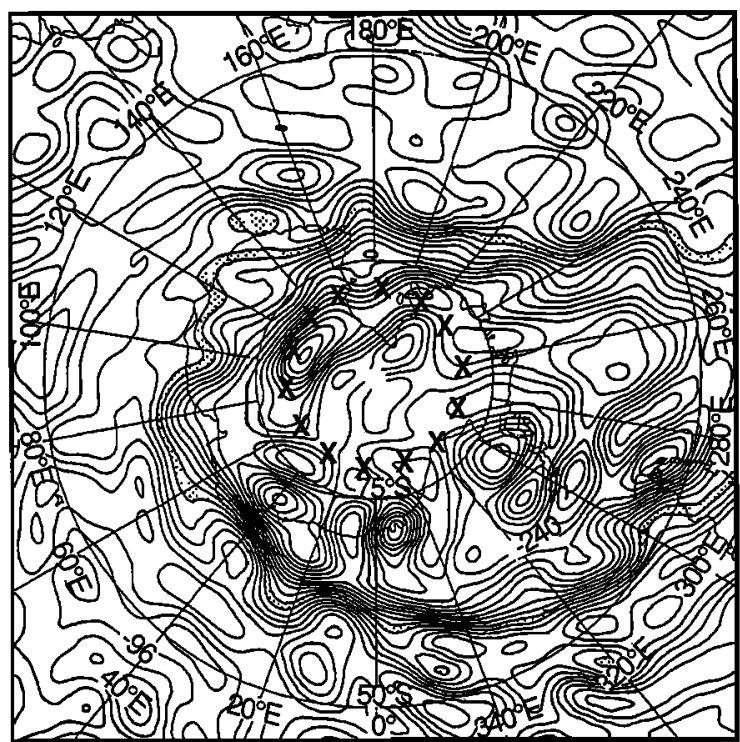

Fig. 2. ECMWF Antarctic analysis on October 22, 1991, (a) 30$\mathrm{mb}$ wind field and (b) $\theta=700 \mathrm{~K}$ potential vorticity. $X ' s$ indicate measurement locations.

winds is at or near this location on all pressure levels in the stratosphere up to $10 \mathrm{mb}$, the highest altitude available from ECMWF, and it is readily apparent that the constant mixing ratio profiles are clearly situated at the vortex center as defined by the zero wind criterion on all days in October for which observations are available. Lower mesospheric air is found only at this location, with higher methane mixing ratios showing the folded structures between 3 and $30 \mathrm{mb}$ occurring further out in the vortex where the wind speeds are greater. Examination of PV maps clearly show that all observations taken on October 22 , 1991 , at $77 \mathrm{~S}$ were within the vortex at all potential temperatures between $400 \mathrm{~K}$ and $700 \mathrm{~K}$. They were also invariably poleward of the wind maximum. These general characteristics were evident on all 7 days (October 11,12,17, 18,22, 23, and 24), and it is further apparent that a strong single vortex was extant with westerly winds of up to $80 \mathrm{~ms}^{-1}$ at all levels in the jet up to $10 \mathrm{mb}$. As Figure $2 \mathrm{~b}$ shows, it is very difficult to associate high $\mathrm{PV}$ values with low $\mathrm{CH} 4$ and high $\mathrm{HF}^{\circ}$ in the air from aloft. This is also true at other potential temperatures down to $400 \mathrm{~K}$. Further, there is no clear indication, using the PV contours, of a vortex center, in contrast to the analyzed wind arrows which make it immediately obvious.

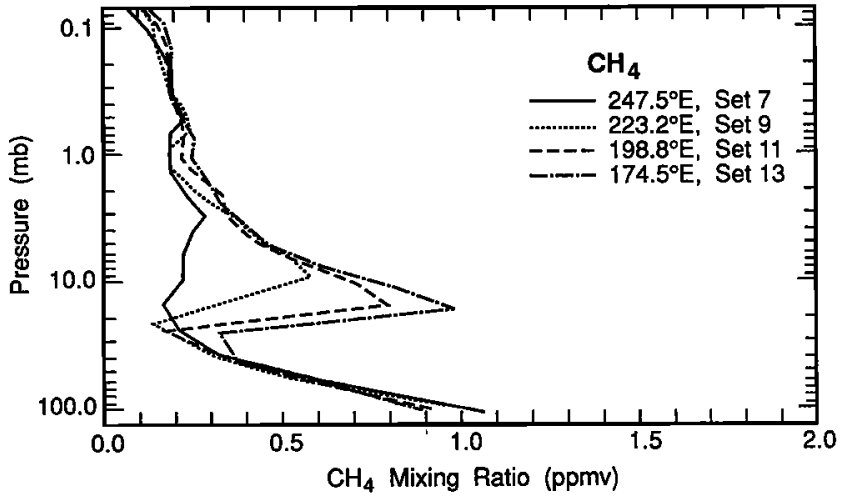

Fig. 3. HALOE pressure versus $\mathrm{CH}_{4}$ mixing ratio, sunset on October 22, 1991 , at $77^{\circ} \mathrm{S}$.

The occurrence of a constant $\mathrm{CH}_{4}$ mixing ratio over such a broad altitude range (65 km to $25 \mathrm{~km}$ ) is highly unusual and, to our knowledge, has not been observed previously. Like ozone, the smallest values occur at the vortex center, and the largest mixing ratios occur nearer the edge at $175^{\circ} \mathrm{E}$. The same can be said of $\mathrm{NO}_{2}$. The HF ordering is reversed, however, with the largest mixing ratio occurring at the vortex center. Methane and HF pressure versus longitude cross sections on October 22 are shown in Figures 5 and 6 , respectively. The region of low $\mathrm{CH}_{4}$ mixing ratio extends over the $2 \mathrm{mb}$ to $\sim 30 \mathrm{mb}$ range and from $\sim 240^{\circ} \mathrm{E}$ to $-360^{\circ} \mathrm{E}$. There is also a local maximum in the $90^{\circ} \mathrm{E}$ to $240^{\circ} \mathrm{E}$ range centered at $\sim 20 \mathrm{mb}$. $\mathrm{HF}$, on the other hand, shows its largest stratospheric values over the $240^{\circ} \mathrm{E}$ to $360^{\circ} \mathrm{E}$ range and a local minimum in the region where $\mathrm{CH}_{4}$ is a maximum. Note the close correspondence of features in the two cross sections, illustrating the excellent suitability of the HALOE $\mathrm{CH}_{4}$ and $\mathrm{HF}$ measurements as tracers. Nitric oxide, $\mathrm{NO}_{2}$, and $\mathrm{O}_{3}$ exhibit the same sense of variation as $\mathrm{CH}_{4}$, while $\mathrm{H}_{2} \mathrm{O}$ varies in a similar way as $\mathrm{HF}$. $\mathrm{HCl}$ shows a maximum in the $240^{\circ} \mathrm{E}$ to $360^{\circ} \mathrm{E}$ range, but no local features are apparent in the $90^{\circ} \mathrm{E}$ to $240^{\circ} \mathrm{E}$ region. This general picture persisted from October 18 through October 26 and for October 11-17 although, during the earlier period, the longitudinal distribution was different. After October 26 , the HALOE measurement sample, which is determined by the spacecraft-earth-sun geometry, moved equatorward of $70^{\circ} \mathrm{S}$. The data show that the $\mathrm{CH}_{4}$ and HF patterns indicated in Figures 3 and 4 persisted up to $62^{\circ} \mathrm{S}$ at least through October 31 , 1991. These patterns were gone by November 3 at $56^{\circ} \mathrm{S}$, which is essentially outside the vortex.

\section{Data Validation}

An intensive data validation effort is being conducted by the HALOE Science Team. Comparisons have been made with past observations, model calculations, and measurements by other

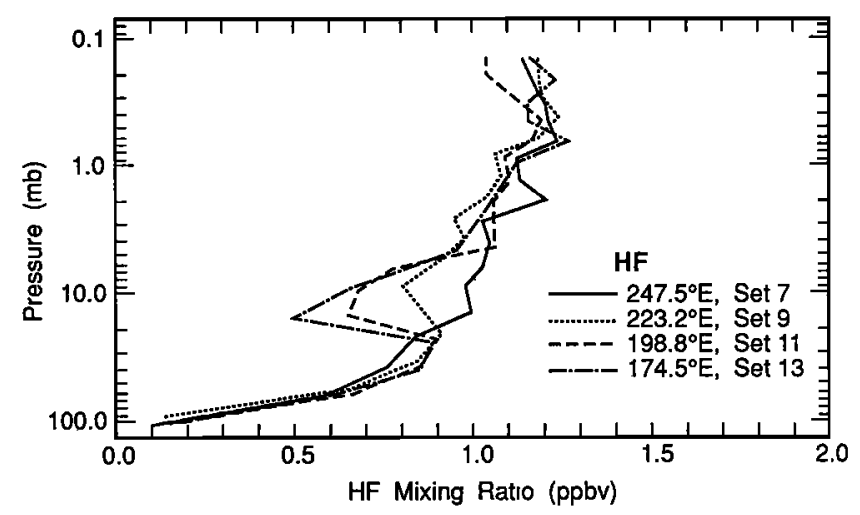

Fig. 4. HALOE pressure versus HF mixing ratio, sunset on October 22,1991 , at $77^{\circ} \mathrm{S}$. 


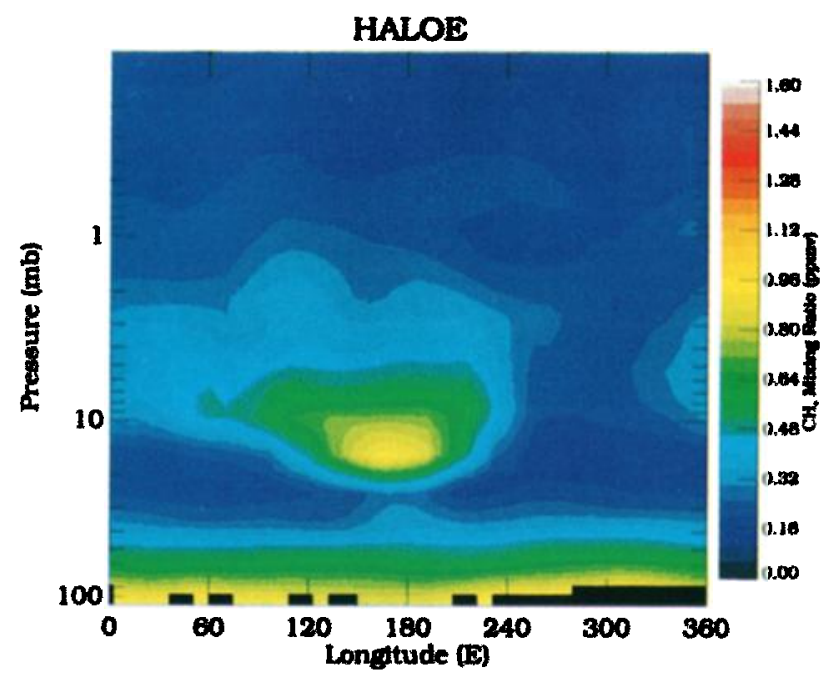

Fig. 5. $\mathrm{CH}_{4}$ pressure versus longitude cross section, sunset on October 22,1991 , at $77^{\circ} \mathrm{S}$.

UARS experiments. In addition, a few comparisons have been performed for balloon and aircraft observations. In all cases, for all HALOE parameters being measured, the agreement is good (on the order of $\sim 20 \%$ or less differences). A paper by Tuck et al. [1993] compares $\mathrm{HALOE} \mathrm{CH}_{4}$ and $\mathrm{H}_{2} \mathrm{O}$ data with results from the 2nd Airborne Arctic Aircraft Expedition (AASE-II). These results agree to within $13 \%$ or better. Based on these comparisons and our error studies, we conclude that the state of validation is sufficient to establish the correctness of the variations we are reporting.

Aerosol effects which can contaminate signals and cause increased mixing ratio errors are small or negligible in the Antarctic region over most of the time period discussed here. The data show that some high altitude $(\sim 25 \mathrm{~km})$ aerosol layers are present, but the absorption occurs in well-defined layers and the data have been screened sufficiently so that any artificial retrieval effects due to aerosols will not change the character of the features we have discussed.

\section{Discussion}

The constant $\mathrm{CH}_{4}$ mixing ratio profile with a low value $(\sim 0.25$ ppmv) implies that unmixed vertical descent at the vortex center is occurring, and this was invariably observed during the entire

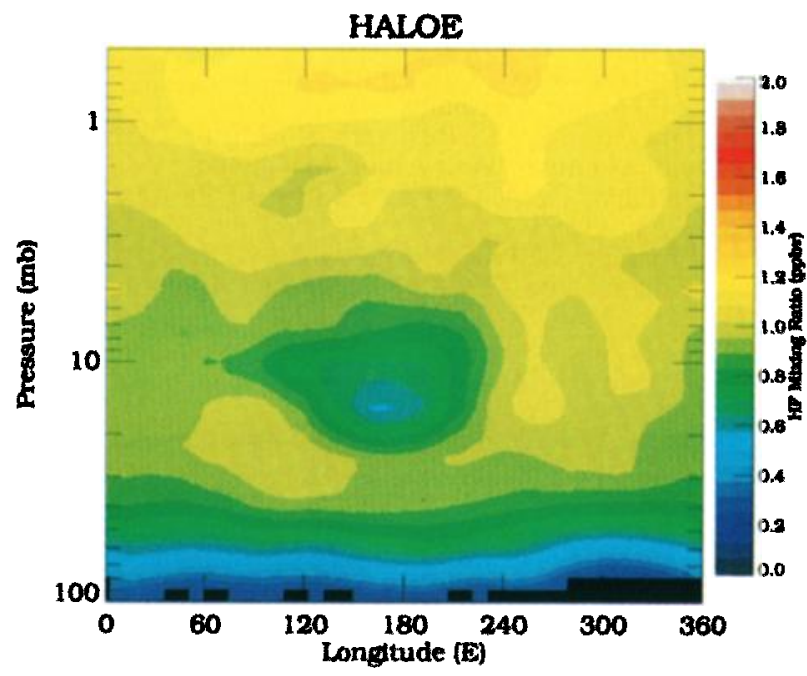

Fig. 6. HF pressure versus longitude cross section, sunset on October 22 , 1991, at $77^{\circ} \mathrm{S}$.

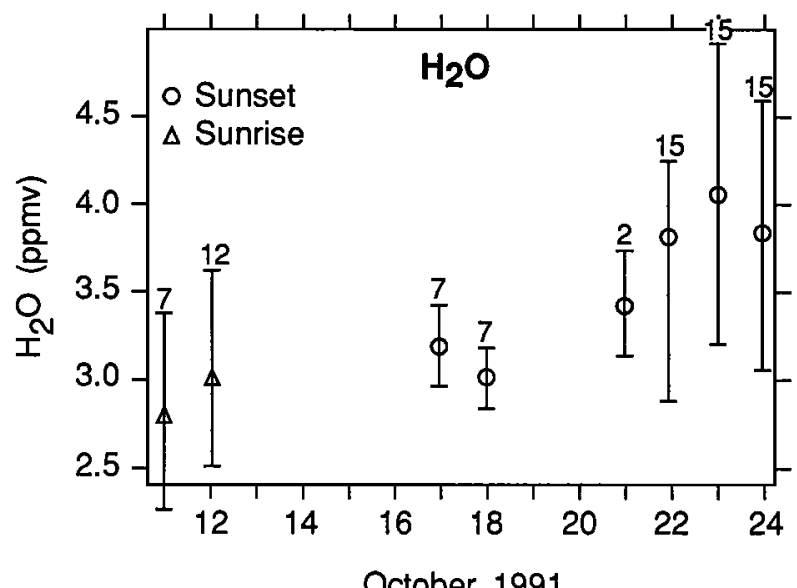

Fig. 7. $\mathrm{HALOE} \mathrm{H}_{2} \mathrm{O}$ Antarctic observations averaged over the $15-20 \mathrm{~km}$ altitude range for $74^{\circ} \mathrm{S}$ to $80^{\circ} \mathrm{S}$. Vertical bars are standard deviations of event means. Numbers indicate number of events.

month of October. The only region in the vortex where the low values occur $\left(240^{\circ} \mathrm{E}-360^{\circ} \mathrm{E}\right)$ is in the vortex center as defined by the geographical position of zero winds where unmixed descent could be expected. The other variations reported are consistent with this explanation. $\mathrm{HF}-, \mathrm{HC} \ell$-, and $\mathrm{H}_{2} \mathrm{O}$-enriched air and $\mathrm{NO}$ - and $\mathrm{NO}_{2}$-poor air brought down from above would cause the patterns that are shown by the data for the $240^{\circ} \mathrm{E}$ to $360^{\circ} \mathrm{E}$ region (i.e., enhanced $\mathrm{HF}, \mathrm{HC} \ell$, and $\mathrm{H}_{2} \mathrm{O}$, but depressed $\mathrm{NO}$ and NO2). The concave upward curvature of the HF contours, as well as those of $\mathrm{HC} \ell, \mathrm{NO}$, and $\mathrm{NO}_{2}$ not shown in this paper, also support the idea of horizontally unmixed vertical descent. The timescale for this vertical descent to occur is of interest; even if it had taken place over the whole period since vortex spin-up in March and April, the descent rate implied is about a scale height per month, and this rate is a lower limit assuming no horizontal mixing occurred over a half a year, a rather unlikely state of affairs. These descent rates are very large and are in line with the observationally based predictions of Danielsen and Houben [1988] and the deduced rates of Tuck [1989] and Proffitt et al. [1989b]. Recently, O'Neill et al. [personal communication, 1992] have corroborated this descent of mesospheric air into the stratosphere over a time scale of a few months using a numerical primitive equation model. The observed radial gradients of $\mathrm{CH}_{4}$ increase outward from the position of zero winds (the vortex center). The balance between descent and meridional motion must be such as to maintain unmixed air from aloft at the vortex center with increasing mixing ratio radially outwards towards the jet. To our knowledge, no model has reproduced this structure. The inhomogeneity with longitude and altitude inside the vortex during October also undermines attempts to treat polar ozone loss by applying the law of mass action to the vortex as though it was a single, well-stirred air mass.

The ozone hole is generally evident in the HALOE data between 12 and $25 \mathrm{~km}$, and the expected signatures, e.g. dehydration, low $\mathrm{O}_{3}$, low $\mathrm{NO}_{2}$, are indeed observed on the days for which observations exist within the vortex, namely October 11 and 12 (sunrises) and October 17-18, and 21-24 (sunsets). Any time trend during this period is of interest, and the lower stratosphere time history of the zonal average $\mathrm{H}_{2} \mathrm{O}$ mixing ratio between 15 and $20 \mathrm{~km}$ is accordingly shown in Figure 7. Both water and ozone (not shown because of space limitations) show substantial recovery from "ozone hole" conditions during the 13 days. During the 13 days, the area of the vortex bounded by the $-24 \mathrm{PV}$ units contour at $\theta=425 \mathrm{~K}$ (approximately at the center of the $15-20 \mathrm{~km}$ region) decreased by $7.7 \%$ from 29.9 million square kilometers on October 11 to 27.6 on October 24 (the PV map was provided by the ECMWF). Since all the observations on these dates were at latitudes and PV levels which occur within the vortex, the recovery in $\mathrm{H}_{2} \mathrm{O}$ must have a substantial component arising from descent of 
undehydrated air from aloft, in addition to the horizontal component arising from the $7.7 \%$ erosion of the vortex. The time behavior of the average water vapor mixing ratios, increasing from $2.7 \mathrm{ppmv}$ to $4.0 \mathrm{ppmv}$ between October 11 and October 24 , clearly demonstrates that air is being resupplied to the ozone hole with a dynamical time constant of approximately 30 days. The same number is obtained by using $\left(2 \mathrm{CH}_{4}+\mathrm{H}_{2} \mathrm{O}\right)$ a conservative quantity. The great inhomogeneity within the vortex necessarily makes the time constant approximate, but it is of the same magnitude as the time constant of the chemistry which destroyed the ozone during late August and September. The ozone in the same region shows an increase from about $0.7 \mathrm{ppmv}$ to $1.4 \mathrm{ppmv}$ and is due to a combination of chemical regeneration and dynamical effects (i.e., resupply of undehydrated relatively ozone-rich air). This gives a shorter recovery time constant of 19 days, which has a 30-day dynamical resupply component (as indicated by the $\mathrm{H}_{2} \mathrm{O}$ changes), with the remainder presumably due to chemistry.

The cause of the local maximum in $\mathrm{CH}_{4}, \mathrm{NO}_{2}$, and $\mathrm{O}_{3}$ and local minima in $\mathrm{HF}$ and $\mathrm{H} 2 \mathrm{O}$ in the $90^{\circ} \mathrm{E}$ to $240^{\circ} \mathrm{E}$ range and at pressures between 3 and $30 \mathrm{mb}$ is an interesting problem. The observed mixing ratios of $\mathrm{CH}_{4}, \mathrm{HF}$, and $\mathrm{H}_{2} \mathrm{O}$ in this region have values which are characteristic of mid-latitude air. Note that these features occur nearer the vortex edge, but still within it (see Figure 2 and note that the observations were taken at $77^{\circ} \mathrm{S}$ ). Examination of ECMWF charts of PV at potential temperatures in the range $400 \mathrm{~K}<\theta<700 \mathrm{~K}$ shows that the maximum $\mathrm{PV}$ gradient and the maximum wind speed both occur equatorward of these features at the longitudes where they appear. A possible explanation of the data, which is internally consistent, is that low-latitude air is transported into the vortex region on an isentropic surface centered at about the $20-\mathrm{mb}$ level. This is supported by the poleward latitudinal gradient which exists for $\mathrm{HF}$ and $\mathrm{H}_{2} \mathrm{O}$, but equatorward gradient exhibited by $\mathrm{CH}_{4}, \mathrm{NO}_{2}$, and $\mathrm{O}_{3}$. Poleward transport of air would create the features shown by the data in the $90^{\circ} \mathrm{E}$ to $240^{\circ} \mathrm{E}$ region. While the mechanism for this transport is as yet unexplained, one idea on how this might occur has been advanced by Danielsen and Houben [1988], who discussed the dynamics of lower latitude, ozone-rich air moving poleward and downward as it approaches the polar night jet. Note that the region inside the vortex having the characteristics of mid-latitude air is bounded above and below and to the east and west by vortex air. We further note that the vortex did not break down until well into November [see e.g. Krueger et al., 1992].

The plausibility of low-latitude air being transported into the vortex can be supported by comparison of HALOE measurements taken both outside and inside the vortex. It is not possible to do this comparison on October 22 using HALOE data since the other HALOE measurement latitude on this day was in the opposite hemisphere at $25^{\circ} \mathrm{N}$. Four days previously on October 18 , however, measurements were made at $79.7^{\circ} \mathrm{S}$ and between $26^{\circ} \mathrm{S}$ and $33^{\circ} \mathrm{S}$. An obvious molecule for the evaluation is the long-lived tracer $\mathrm{CH}_{4}$. Comparison of the high $\mathrm{CH}_{4}$ features inside the vortex (i.e., like sets 9,11 , and 13 in Figure 3 ) on October 18 with profiles measured between $26^{\circ} \mathrm{S}$ and $33^{\circ} \mathrm{S}$ show mid-latitude air with mixing ratios characteristic of the vortex profile features over the same altitude range. The same is also true for the other tracer, HF, thereby lending support to the explanation that mid-latitude air has moved horizontally into the vortex in the middle stratosphere.

\section{Summary}

The HALOE data described in this paper show some unusual phenomena in the early-to-late October Antarctic spring period. The data are internally consistent with the occurrence of unmixed vertical descent taking place at the vortex center, as predicted by Danielsen and Houben [1988]. This is manifested most clearly by a constant $\mathrm{CH}_{4}$ vertical mixing ratio profile located at the geographical position of minimum winds, 1.e., the vortex center. No such obvious correlation exists with PV contours. Also, the data show air inside the vortex which has mixing ratios characteristic of the mid latitudes. Data validation studies conducted to date verify the correctness of the variations reported to at least the $20 \%$ level. Methane and $\mathrm{H}_{2} \mathrm{O}$ have been validated to $13 \%$ or better by comparison with ER-2 observations. The time constant for the resupply of air to the ozone hole in the lower stratosphere $15-20 \mathrm{~km}$ region during October 1991 was about 30 days. The $\mathrm{H}_{2} \mathrm{O}$ recovery must surely occur dynamically, while the ozone restoration, since its time constant is shorter, presumably is driven by both dynamics and chemistry. More extensive time series studies are underway to determine time constants for $\mathrm{O}_{3}, \mathrm{NO}_{x}, \mathrm{H}_{2} \mathrm{O}, \mathrm{HC} \ell$, and $\mathrm{HF}$ during October. These studies should further elucidate the mechanisms operating during this phase of the ozone-hole recovery.

Acknowledgment. The authors are grateful to T. Davies of the ECMWF for providing the wind and potential vorticity fields.

\section{References}

Danielsen, E. F. and H. Houben, Dynamics of the Antarctic stratosphere and implications for the ozone hole, Anthropogene Beeinflussung der ozonschicht, 191-242, DECHEMA, Frankfurt-am-Main, 1988.

Juckes, M. N. and M. E. McIntyre, A high resolution one-layer model of breaking planetary waves in the stratosphere, Nature, $328,590-596,1987$

Krueger, A. J. et al., The 1991 Antarctic ozone hole: TOMS observations, Geophys. Res. Lett., 19, 1215-1218, 1992.

Proffitt, M. H. et al., High-latitude ozone loss outside the Antarctic ozone hole, Nature, 342, 233-237, 1989a.

Proffitt, M. H. et al., Evidence for diabatic cooling and poleward transport within and around the 1987 Antarctic ozone hole, $J$. Geophy. Res., 94, No. D14, 16,797-16,813, 1989 b.

Russell, J. M. III et al., The Halogen Occultation Experiment, $J$. Geophys. Res. Special Issue on UARS, In press, 1993.

Schoeberl, M. R. et al., The structure of the polar vortex, $J$, Geophys. Res., 97, 7859-7882, 1992.

Solomon, S., Progress toward a quantitative understanding of Antarctic ozone depletion, Nature, 347, 347-354, 1990.

Tuck, A. F., Synoptic and chemical evolution of the Antarctic vortex in late winter and early spring 1987, J. Geophys. Res., 94, No. D4, 11,687-11,737, 1989.

Tuck, A. F. et al., Polar stratospheric cloud processed air and potential vorticity in the northern hemisphere lower stratosphere at mid latitudes during winter, J. Geophys. Res., 97, No. D8, 7883-7904, 1992.

Tuck, A. F. et al., Intercomparison of HALOE and ER-2 aircraft $\mathrm{H}_{2} \mathrm{O}$ and $\mathrm{CH}_{4}$ observations collected during the Second Airborne Arctic Stratospheric Experiment (AASE-II), Geophys. Res. Lett., In press, 1993.

R. J. Cicerone, Geosciences Department, 220 Physical Sciences Bldg., University of CA/Irvine, Irvine, CA 92717

P. J. Crutzen, Max-Planck-Institute fur Chemie, Postfach 3060, D-6500 Mainz, Germany

S. R. Drayson, Space Research Building, 2455 Hayward, University of Michigan, Ann Arbor, MI 48105

L. L. Gordley, G\&A Technical Software, 28 Research Drive, Hampton, VA 23665

J. E. Harries, SERC, Rutherford Appleton Laboratory, Chilton, Didcot, Oxon, OX11 OOX, United Kingdom

J. H. Park, Mail Stop 401A, NASA Langley Res. Center, Hampton, VA 23681-0001

J. M. Russell III, Mail Stop 401B, NASA Langley Research Center, Hampton, VA 23681-0001

A. F. Tuck, NOAA Aeronomy Laboratory, Code R/E/AL6, 325 S. Broadway, Boulder, CO 80303

Received December 14, 1992

Revised February 4, 1993

Accepted March 2, 1993 